\title{
Interactive biventricular modeling tools for clinical cardiac
} image analysis

\author{
Hoi-Ieng H Lam*1, Brett R Cowan², Martyn P Nash ${ }^{1}$ and Alistair A Young ${ }^{2,3}$
}

Address: ${ }^{1}$ Auckland Bioengineering Institute, University of Auckland, Auckland, New Zealand, ${ }^{2}$ Auckland MRI Research Group, University of Auckland, Auckland, New Zealand and ${ }^{3}$ Auckland Bioengineering Institute, Auckland, New Zealand

* Corresponding author

from 13th Annual SCMR Scientific Sessions

Phoenix, AZ, USA. 21-24 January 2010

Published: 21 January 2010

Journal of Cardiovascular Magnetic Resonance 2010, I2(Suppl I):P248 doi:10.1 186/I532-429X-I2-SI-P248

This abstract is available from: http://jcmr-online.com/content/I2/SI/P248

(c) 2010 Lam et al; licensee BioMed Central Ltd.

\section{Introduction}

Guide point modeling of the left ventricle (LV) [1] can accurately obtain LV function parameters by interactively fitting a deformable LV finite element (FE) model to a few user-defined data points ("guide points") on MR images. However, functional measurements of the right ventricle (RV) are also essential for fully understanding cardiac function.

\section{Purpose}

To develop interactive guide point modeling techniques for fast and efficient clinical evaluation of biventricular function.

\section{Methods and results}

Stevens et al. [2] developed a biventricular FE model of an isolated arrested pig heart which consists of 88 hexahedral elements with tricubic interpolation (Fig. 1(a)). Since clinical estimation of transmural motion is limited to a single thickness measure, we reduced the model's geometric complexity from having 1977 degrees of freedoms (DOFs) per geometric coordinate field to 629 by using a bicubic-linear interpolation scheme. This simplified model was fitted to 3D image data from a normal human volunteer using linear least square minimization (Fig. 1 (b) \&1(c)). To accelerate the solution time of the guide point modeling analysis, we added 192 computer-generated data points ("phantom points") whose initial positions are evenly distributed on the surfaces of the simplified model. During the interactive guide point modeling analysis, the phantom points are updated based on global shape changes extrapolated from the guide points using a single-element trilinear FE model. The biventricular model is fitted to both the guide points and the phantom points, with lower weights applied on the phantom points than the guide points to ensure that the model is fitted closely to the user inputs. The solution time is four times faster after the introduction of phantom points.

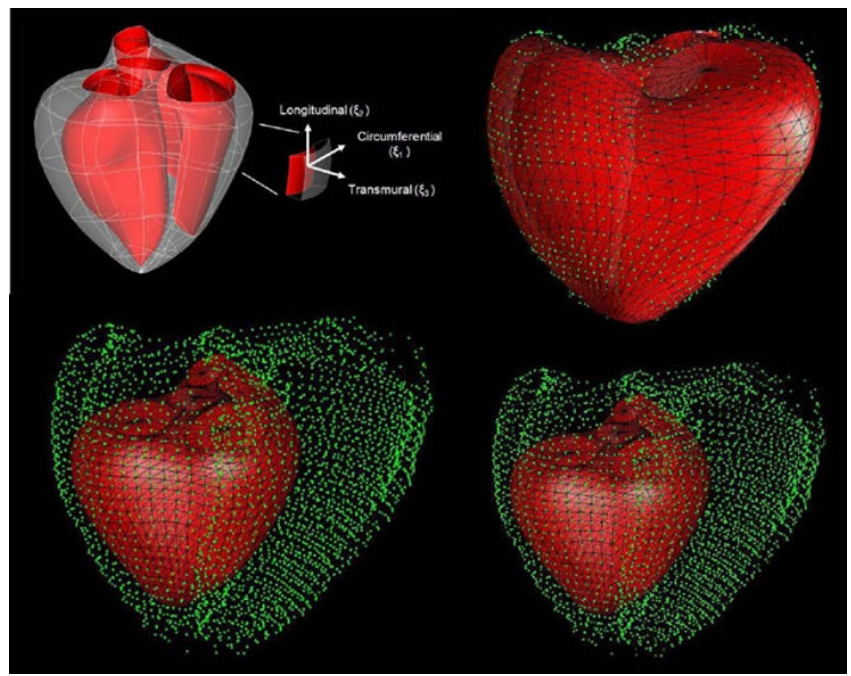

Figure 1

(a) Porcine biventricular FE model [2]; (b) displayed (epicardial surface in red) with target human data cloud (green points); (c) fitted to the human data cloud. 


\section{Conclusion}

We have developed a human biventricular model for efficient interactive clinical cardiac analysis, whereby the guide point modeling technique was extended to incorporate computer-generated data points. These methods will aid the cardiac function assessment of patients with right ventricular dysfunction, such as those with congenital heart disease (Fig. 2).

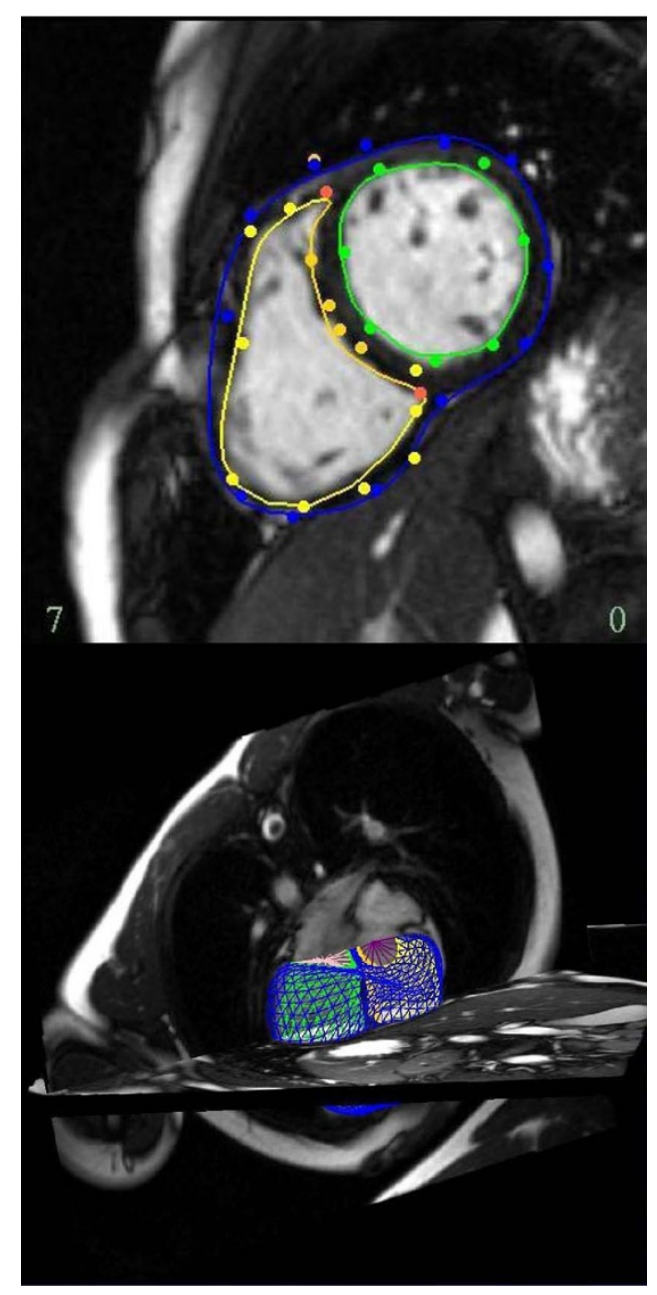

Figure 2

Interactive guide point fitting of the human biventricular model to a congenital heart disease patient (left) and the fitted model in 3D with short and long axis MR images (right).

\section{References}

I. Young AA: Radiology 2000, 216:597-602.

2. Stevens C: Journal of Biomechanics 2003, 36(5):737-748.
Publish with Biomed Central and every scientist can read your work free of charge

"BioMed Central will be the most significant development for disseminating the results of biomedical research in our lifetime. "

Sir Paul Nurse, Cancer Research UK

Your research papers will be:

- available free of charge to the entire biomedical community

- peer reviewed and published immediately upon acceptance

- cited in PubMed and archived on PubMed Central

- yours - you keep the copyright
BioMedcentral 